\title{
The patient-healthcare worker relationship: how does it affect patient views towards vaccination during pregnancy?
}

Rose Jane Wilson, Dr. Tracey Chantler, Dr. Shelley Lees, Dr. Pauline Patterson, Dr. Heidi Larson

rose.wilson@1shtm.ac.uk

tracey.chantler@1shtm.ac.uk

shelley.lees@1shtm.ac.uk

pauline.paterson@1shtm.ac.uk

heidi.larson@1shtm.ac.uk

All authors are based at the London School of Hygiene and Tropical Medicine (LSHTM)

\section{Funding}

This research was funded by the National Institute for Health Research Health Protection Research Unit (NIHR HPRU) in Immunisation at LSHTM, in partnership with Public Health England (PHE). The views expressed are those of the authors and not necessarily those of the NHS, the NIHR, the Department of Health or of Public Health England.

\section{Acknowledgements}

I would like to acknowledge the Brocher Foundation in Geneva for hosting me and giving me the time and space to analyse and write up my research. I am also extremely grateful to Dr. Sophie Zadeh for introducing me to the theory of relational autonomy. 


\begin{abstract}
Purpose: Relational autonomy proposes that persons are socially embedded, with decisions being made within social relationships. Through this theoretical lens, this article explores how the healthcare professional-patient relationship can affect pregnant women's decisions to accept pertussis and influenza vaccines.
\end{abstract}

Methodology/Approach: Hackney was chosen as the study site as it has very low vaccine uptake rates. In-depth interviews were conducted with 40 pregnant and recently pregnant women, as well as ten healthcare professionals. Interviews explored experiences of NHS healthcare, and views towards vaccination in pregnancy. An observation of a consultation between a pregnant patient and her GP was also conducted in order to understand how the vaccination discussion takes place.

Findings: The findings of this study indicate that advice from friends and family can greatly influence a pregnant woman's vaccination decisions. The patient's social context, including influences on her decisions, must be understood by healthcare professionals, so that discussions about concerns can take place. If close relationships with patients are formed, healthcare professional advice is more likely to be trusted. With support from healthcare professionals, patients feel competent, empowered to make the right decision for them, and are more likely to vaccinate.

Research limitations/implications: This research will help to inform contextualised policies aimed at increasing vaccination acceptance and reducing inequality in access to vaccination during pregnancy in Hackney.

Originality/Value of Paper: To the author's knowledge, this paper is the first to apply the theory of relational autonomy to views towards maternal vaccination and decision-making. It provides valuable insights into how healthcare professionals' interactions with their pregnant patients can influence vaccination acceptance. The paper contains advice on how both 
healthcare professionals and policy-makers can include mothers in vaccine decision-making processes in more personalised ways, by adopting a dialogue that appreciates and understands the social processes around vaccination concerns.

Key words: Maternal vaccination, relational autonomy, healthcare professional-patient interaction, pertussis, influenza 


\section{Introduction}

Pertussis and influenza are preventable diseases with potentially severe consequences for newborn infants and in the case of influenza, for pregnant women. Infants under the age of six months are vulnerable to transmission of pertussis and influenza infection from others, especially their mothers (McIntyre P and N, 2009). Influenza immunisation was first recommended for all pregnant women in 2009 (Dlugacz Y et al., 2012) and due to a pertussis (whooping cough) outbreak in 2012, which caused 14 infant deaths, the UK Department of Health temporarily introduced pertussis vaccination for all pregnant women (Flory, 2012).

A systematic literature review of 155 articles relating to acceptance of vaccines provided during pregnancy, showed that little research has been conducted into how pregnant patients' social context and relationships with others, especially their healthcare workers (HCWs), affects vaccination acceptance (Wilson RJ et al., 2015). In this paper, I (RW) explore, in relation to the theory of relational autonomy, how the patient-HCW relationship can affect general trust in HCW advice, and thus vaccination, which could affect vaccine acceptance during pregnancy. I also explore other influences on vaccine decision-making and how these should be taken into account in patient-HCW encounters. I start my paper by analysing the various social influences on pregnant women's vaccination decisions. I then explore the influence of trust in government, the NHS and healthcare professionals on vaccination acceptance, and how vaccination acceptance is shaped by communities' historical and sociopolitical contexts. I illustrate this point through narratives of Black British Caribbean women interviewed. Finally, I analyse how empowerment, in a way that is related to theories of relational autonomy, can help in the vaccine decision-making process. These are particularly important issues in today's chaotic care environment, with changes to organisational structures, time limitations, staff shortages, mandatory overtime, and lack of continuity, 
where it is sometimes difficult to practice in a manner that fosters partnership, or provides support to patients (Ritchie B et al., 1997).

Relational autonomy is a feminist formulation of autonomy which presents a different way of thinking about autonomy that is relational rather than individualistic (Walter JK and Friedman Ross L, 2014), accepting that persons are socially embedded, with their identities being formed within social relationships and shaped by intersecting social determinants such as race, class, gender and ethnicity (Mackenzie C and Stoljar N, 2000). This approach opposes the current emphasis on the individual's ability to access and acquire skills, where patients who do not conform to this model are alluded to as apathetic and ignorant, needful of persuasion to change their behaviour, resistant to change and 'hard to reach' (Leach $\mathrm{M}$ and Fairhead J, 2007). Rather, relational autonomy understands that dialogue, especially with HCWs, which involves advice-giving, is not an affront to individual autonomy, but allows individual autonomy to flourish (Walter JK and Friedman Ross L, 2014).

All names used in this paper are pseudonyms.

\section{Fieldwork and Interpretive Approach}

The borough of Hackney, London was chosen as it has one of the lowest vaccine coverage rates among pregnant women in England, with influenza vaccine coverage rates at $31.3 \%$ (Public Health England, 2016) and pertussis coverage rates at 27.4\% (Byrne L, 2015). Hackney is also very ethnically and socially diverse. According to the 2011 Census, just over a third $(36 \%)$ of respondents in Hackney described themselves as White British. The remaining population consists of black and minority ethnic groups, with the largest group Other White, $16.3 \%$ followed by Black African, $11.4 \%$ and Black Caribbean people $7.8 \%$. Hackney has the largest group of Charedi Jewish people in Europe, which represents about $7.4 \%$ of the borough's overall population. At least $4.5 \%$ of the Hackney population is 
Turkish. Other significant communities in Hackney include Chinese, Vietnamese and Eastern Europeans especially Polish, Western Europeans particularly Spanish and French people, Australasians and residents from North, and Latin America (LB Hackney Policy Team, 2016). Hackney is an area of growing economic opportunity, however, this growth sits alongside significant deprivation, with persistent inequalities and child poverty, unemployment and welfare dependency in some areas (LB Hackney Policy Team, 2016).

Participants were recruited from nine parent toddler groups across Hackney, which were free to attend; four community centres/migrant support groups, three GP practices with median vaccination uptake rates and a diverse patient population (according to Public Health England (PHE) data); and two community antenatal clinics.

Semi-structured interviews were conducted between December 2016 and June 2017, with forty pregnant women and women who had given birth in the past year at the commencement of the fieldwork, as well as ten HCWs. Where necessary, an interpreter attended the interviews. In addition, one consultation between a pregnant patient and her GP was video recorded. The video recording acted as an ethnographic observation method which allowed the exploration of interactions between HCWs and pregnant women. It must be noted however that the Hawthorne effect (Mayo E, 1949) may have occurred with this method, as the GP being video recorded knew that the study was looking at vaccine discussions and so would have been more likely to bring it up in the consultation.

Pregnant and recently pregnant participants interviewed were between ages 18 and 41 and were from a wide variety of backgrounds. Fifteen out of 40 participants described themselves as white British, five were Black British Caribbean, two were Black British, two Chinese, 
two German, two Nigerian, two Orthodox Jewish, two Turkish, one was Australian, one British Brazilian, one Italian, one Lithuanian, one Norwegian, one Pakistani British, one Somalian and one was South African. Sixteen participants had not undergone higher education, nine had a bachelor's degree and 15 had a master's degree. The participant who took part in the video recording of the consultation, was age 34, White British and employed. Healthcare professionals interviewed were all female and between age 23 and 62. Five were White British, two were Black British Caribbean, two were British Indian and one was Black British. Six participants were General Practitioners (GPs), two were midwives and two were practice nurses.

Data was analysed using a thematic analysis approach. Thematic analysis is often utilised when research is used in policy, and thus must be accessible to those outside of academia (Braun V and Clarke V, 2014). Thematic analysis was used in this study as a "contextualist" method, characterised by theories of constructionism and critical realism, which acknowledge the ways individuals make meaning of their experience, and, in turn, the ways the broader social context impinges on those meanings, while retaining focus on the limits of "reality" (there is no singular, objective, universal truth, waiting to be uncovered through the application of 'the scientific method. Instead, there is a multiplicity of interrelated, subjective and often oppositional understandings) (Taylor GW and Ussher JM, 2001). Therefore, thematic analysis conducted within a constructionist framework does not seek to focus on motivation or individual psychologies, but instead, to theorise the socio-cultural contexts, and structural conditions, that enable individual accounts (Braun V and Clarke V, 2014). Using thematic analysis, themes within the interviews and video-recording were identified and analysed in rich detail. A detailed and nuanced account of one particular theme within the 
data (Patient-HCW interaction) was conducted, which relates to a specific question and area of interest within the data: how relational autonomy affects acceptance of vaccines.

\section{Impact of social influences on vaccination decisions}

I spent a lot of time in participant's homes and at their local cafés, chatting over tea and crying babies, about their experiences using the healthcare system during pregnancy and their views towards vaccination. In this section, I will explore in depth, the various social influences on patient's decisions, and the importance of HCWs to understand these influences and build their own relationships with patients.

When asked who made decisions about their health, all 40 women interviewed immediately and proudly said 'me'. However, later on in the interview, when asked if there was anyone or anywhere they would typically go to for advice regarding their health or specifically, vaccination, all participants mentioned a friend or family member, as well as, or rather than her GP. While these answers seem to contradict each other, relational autonomy suggests that, due to the nature of 'society' and the idea that no-one is completely individual or untouched by others, one can engage with others in important health decisions and value their input, while still feeling autonomous. This is especially true if those engaging in the conversation are trusted friends, family members or healthcare providers. According to Walter et al., (2014), discussion of challenging decisions with various social contacts in fact increases feelings of autonomy as it allows an in-depth exploration of the issue and thus empowers the individual to make the 'right' decision for them (Walter JK and Friedman Ross L, 2014). 
Participants often had very close relationships with female family members such as sisters who already had children, mother-in-laws, mothers and aunts. It seemed that the participants were not looking for actual information from these contacts, as they would with a HCW, instead they wanted personal interaction and to feel comfortable and cared for.

My mother-in-law she could tell me quite a lot... she's had a lot of kids... My mum's only had one... and my mum seems to know a lot, probably because she's looked after kids in the past...It doesn't mean because you've only had one you don't know, so no matter what, I go to my mum (Beth, age 22).

This participant had support from her mother, mother-in-law and partner in making her vaccination decision. She also had a good relationship with her midwife and said that all of her friends had been vaccinated. Possibly as a result of these trusted influences, who had positive attitudes towards vaccination, the participant also trusted vaccination.

This desire for personal interaction was also seen in the participants' wide use of internet forums, especially Mumsnet and Netmums, often before seeking advice from their GP. Many participants said they used such forums but at the same time were quick to criticise incorrect information and the opinions of other users who are all going a bit potty (mother, age 34). These forums and other internet sites provided an extension to mothers' 'real life' social networks, enabling them to discuss or just read about other people's opinions towards pregnancy issues and vaccination. These internet forums often became personified as a best friend, even if it was acknowledged that this relationship was not always healthy. 
Within my pregnancy, that internet became my best friend, and it gave me information I didn't really want to know, but it wasn't actually... the right information. So, I was always told not to always believe everything that's on Google, because it's not $100 \%$ accurate... so you never know if it's the truth (Lucy, age 27).

The media has often portrayed mothers' opinions as driven by emotion, and fathers' opinions influenced by 'scientific evidence' (Leach M and Fairhead J, 2007). However, participants in my study often laughed and employed a rather patronising attitude towards her male partner's understanding of vaccination and pregnancy, and illustrated that they themselves were in control of their body.

My partner doesn't factor in... I read, when I was pregnant... an article... this man is, like... "when my wife was pregnant, I discovered all the things she couldn't eat, so I had to cook her a special meal every night..." I'd have murdered him if he'd said anything like this... I know some people feel like it's their [partner's] baby. But, I don't... When it's inside me, it's my baby (Rita, age 27).

Women therefore tended not to seek advice from male partners as much as from their female friends and family members, thus sometimes excluding male partners from the vaccine decision-making process. Through extended time spent between HCWs and pregnant patients over the course of the pregnancy, in-depth discussions could be facilitated, which could enable HCWs to understand these influences and the patient's background and social context more broadly, thus identifying any specific vaccination concerns. 


\section{Understanding the importance of trust in the government, the NHS and the healthcare worker}

You're putting your whole trust in these people... to make sure that you come through the other end perfectly fine (mother, age 27).

'Trust' in this sense can be defined as an acceptance of decisions without questioning the rationale behind them (Löfstedt RE, 2005). However, my research demonstrated that notions of trust and distrust are complex. Distrust in government motivation to vaccinate was evident when participants expressed that vaccination is only pushed so that healthcare workers do not go off sick (mother, age 34), and to stop hospital admissions in order to save money (mother, age 34). This distrust became palpable in the use of metaphors by participants when speaking about vaccination. Metaphors are important because they are influenced by wider sociopolitical discourses in society and are unconsciously drawn on as ways of thinking that have always been, and continue to be acceptable to the groups with which individuals identify, when perceived risks are encountered. When such events are objectified, groups favour the symbols and/or metaphors compatible with in-group values (Joffe H, 2003). In analysing vaccine anxieties, we must therefore understand how parents conceptualise the bodily processes involved in keeping healthy and how, in their context, they consider vaccines. This involves understanding the concepts and metaphors parents use and how their framings integrate bodily, social and political reflection (Leach M and Fairhead J, 2007).

Three participants in my study used the term 'guinea-pig' to describe how they felt with regards to being offered vaccines. As well as using this metaphor, one Black British Caribbean mother stated that in accepting vaccination, you are taking "a Russian Roulette chance" that your baby 
would be affected (Shiloh, age 19). In my study, the use of metaphors arose when participants felt strongly against vaccination. Use of powerful metaphors (i.e. guinea-pig, Russian Roulette chance), especially by Black British Caribbean mothers, which have connotations of forced experimentation and violence, as well as participants' recalling stories from family members who, when arriving in the UK, became ill from vaccines, could be linked to distrust in the UK government and the NHS. This is plausible when acknowledging past British-Caribbean colonialism, as well as the relatively recent post-colonial experimentation with the contraceptive pill on Caribbean women with Caribbean women acting as guinea-pigs of one of the most revolutionary drugs in the history of medicine (Oudshoorn N, 2002).

Of the five self-described Black British Caribbean women interviewed, none had accepted the influenza vaccine and only two had (hesitantly) accepted the pertussis vaccine during pregnancy. One Black British Caribbean midwife interviewed (who was against vaccination in pregnancy herself) mentioned that more Afro-Caribbean women than white women decline vaccination due to distrust of what's in vaccination, as it is "something that the government are putting in people" (Midwife Renee, age 41). This sentiment was evident in an interview with a British Caribbean mother, who said,

"I read a lot of things of, about the way the, um, vaccines effect people and affect different cultures differently. Different races and things like that. And that concerned me" (Tessa, age 27).

Implicit distrust in vaccination goes deeper than fears of vaccines themselves and are indicative of the socio-political context in which vaccines and those they are intended for are situated (Leach M and Fairhead J, 2007). In the early $20^{\text {th }}$ century, many vaccine anxieties reflected the 
fears and concerns of institutions of the colonial state (White L, 2005). Colonial control over African societies and bodies deeply entwined with the establishment of public health regimes including immunisation (White L, 2005). Post-independence, vaccine anxieties have arisen at particular times and places in ways that reflect shifts in local-national state politics, the political economy of neoliberal reforms and the relationships between states, citizens and global institutions (Leach M and Fairhead J, 2007). However, Western researchers have been criticised for investigating women's experiences without considering the impact of colonial legacy, power and social inequalities in the woman-healthcare institution relationship (Kumar R, 2013). Here I analyse the ways Black British Caribbean mothers in my study drew connections between vaccines and wider historical and political issues, and how they represent them in ways that make sense given their everyday experiences (Leach $\mathrm{M}$ and Fairhead J, 2007).

Shiloh and Jane are both young, single, unemployed Black British Caribbean mothers, educated up to NVQ and A level respectively. Below are some examples of their interactions with midwives, GPs and social services.

I was signed on to Social Services...It was like they was just watching me, every move I was making with them...they was looking to see... if you're doing everything right... so it just felt not right... because of my past [domestic violence by ex-partner] and my ex-partner, he came there [hospital] for the first time... because we both thought that was right... all of us... going to these appointments. And soon as I went there with him... they [hospital staff] called Social Services to say I came here with him....and then through that it just felt I had to go the clinic by myself after that (Shiloh, age 19). 
I was told, if you don't... make the child get all their injections that... they can... bring up, like, my background... see if I had a social worker, and social worker can get onto my case because... it's like I'm not protecting the child... that's what I was told by one of my midwives... she's the one that closed my case, after I told her, 'yes, [my daughter] will get all her, um, injections', and she has... these injections are new to me, so for me to just say, yeah, I'm going to give it to [my daughter], it's something that I was kind of being forced to do, without ...thinking about it ... and the same GP...she told me that you need to... and I-I felt intimidated, and I feeled under pressure because she was telling me that... these are the things that can happen if you don't get the child [vaccinated]... (Jane, age 24).

Here, the threat given by the midwife and GP that the state will be involved, in the form of Jane having a social worker 'on her case' if she did not vaccinate her child, was akin to blackmail and led Jane to feeling forced to vaccinate her child without having a chance to consider or discuss it.

Parents with little resources are less able to demand services, less likely to view providers as contributing advice rather than dictating behaviours and are more likely to be reported to state agencies or social workers than privileged parents. Privileged parents do not have to worry so much about these issues and so have more choice in their decisions. They also receive more respect from providers as potential partners in their care (Reich J, 2016).

As mentioned above, perceived risks are often constructed through elements of group attachment and the experiences of these groups and themselves, in terms of both the narratives they are exposed to and past misfortunes. These elements do not distort a 'real risk' but are the 
'reality' in the minds of those who consider the risks (Joffe H, 2003). Shiloh said her mother and aunt advised her against vaccination because "when [her aunt] first came to the country 21 years ago...when she did take the flu jab, she constantly got sick" (Shiloh, age 19). Two other Black British Caribbean mothers also relayed family members' experience and advice about the flu vaccine,

Samantha: I've never had the flu vaccine, but I've had loads of friends, family have it, and it's always negative things. Like even my granddad, they call him for flu vaccines... and he's always grumbling afterwards of like feeling a bit like weak with the flu, and it's kind of like why would I have that if, if I've seen other people go through that? No... especially in a pregnancy as well. You already feel tired and weak.

RW: $\quad$... you said you, you, um, ask your mum if you're not sure what to do. Did you discuss vaccination with her?

Samantha: Yeah... she said "no, don't have it"... She's more like... natural health person, like not to do with medicated stuff... so she's... against that kind of stuff anyway.

RW: $\quad$ And... do you think... what she said influenced your decision? Samantha: I had already made my decision, but... when you talk to her and she's... saying all of this kind of... add[s] to all the things you already thought of (Samantha, age 28). 
Jane: They [healthcare professionals] asked me if I wanted the flu jabs. Um, I told them no, not after my aunty was ill, and my cousin was ill... my aunty advised me not to get the flu jab

RW: $\quad$ You said you had a discussion with your-your aunt about it... do you think... because she advised not to get it... you were influenced by her?

Jane: $\quad$ Yeah... None of my family's got it. None of my family members mentioned anything about it... now, we're Jamaicans, we've got friends, we've got more relatives that's Jamaicans, I've heard it through... So, obviously... if I was [pregnant now], I would get it done because... I've heard it several times now.

RW: $\quad$ Okay... and, how much do you trust the advice given on vaccination by the doctor or midwife.

Jane: $\quad$ I would ask the doctor how she got it done... I would have to see in personal writing that they have had this done... and how many people since this new thing has comed out, has actually got the actual injection... And how much people's been sick from it... so I know if I should ...I just think it's just silly... My dad got the flu the other day... and he had to go to the doctors, and they had to give him some strong medicine... he didn't get the flu jab... I just think it's ridiculous, because anybody can get a flu...So, I don't think that will cure the flu (Jane, age 24).

The above narratives show that distrust in the UK government, the NHS and vaccines are passed down through generations, with family members being very clear that they are against vaccination, thus greatly influencing other family members' decisions to vaccinate. Rather than 
trust and engage with healthcare professionals around this issue, these participants preferred to listen to family advice and the advice of those within their community. This is evident with Jane's comment above: now that she has heard of the vaccine from Jamaican friends and family, she would accept it if she was pregnant again. This is unsurprising given the perceived disapproval of those who do not vaccinate, by some HCW, who sometimes put so much pressure on mothers to vaccinate, that they feel they cannot discuss the decision with their HCW. For example, when Samantha's GP recommended the vaccines, she said that she gave the impression that she would think about receiving them, but had already decided not to accept the vaccines (Samantha, age 28).

Distrust in the government, and therefore the NHS (as a government-funded service), can translate into distrust in healthcare professionals. Again, this matter is nuanced. Some participants reported an extremely positive experience with their GP, nurse or midwife. One particular participant said that her midwife was very supportive and became her friend, always asking the participant how she was and what she had been up to, making her feel welcome and comfortable. This participant also trusted HCW advice on vaccination $100 \%$ (Beth, age 22) and believed that there are no disadvantages to vaccination or side effects. Although this participant had a negative birth experience, she still trusted the NHS, due to her positive antenatal experience and close relationship with her midwife.

These sentiments contrast greatly with the experience of Shiloh, age 19 (who used the guineapig metaphor), who felt that while she was pregnant, she was not a main priority. Apart from having family support, she was isolated; she could not go to antenatal classes as she was moving house and she did not know about parenting classes, even though she would have liked to attend some. Shiloh felt neglected and expressed lack of empathy from her HCW. This 
sentiment of neglect during her pregnancy and the birth ran through Shiloh's entire interview. She felt alone unless her family was with her and defending her; My mum, my sister was at work... I didn't have no one there until my auntie [said]... "she's in pain can't you give her a bit more... paracetamol?" (Shiloh, age 19). Shiloh reported that she and her mother made decisions about her health. She had a great deal of trust in her mother and aunt's advice, which tended to be against vaccination; her mother had found out that a lot of these vaccinations do mess you up during pregnancy (Shiloh, age 19). Additionally, Shiloh's's aunt had told her that when she arrived in the country 21 years ago, she had received the influenza vaccine and now constantly got sick. She needed to clarify that the sickness started when she arrived in the country, resonating with the sentiments of distrust in the UK government. The higher level of trust in advice from family over that of HCWs was also evident when she attributed the survival of her son to her mother and aunt;

They didn't concentrate on my pregnancy, all they were worried about [was]... your baby has a lot of hair... and my auntie was like ..."can't you see that the coil is wrapped around his neck? ... get the coil off his neck..." if it wasn’t for my aunt and my mum... he wouldn't be here (Shiloh, age 19).

When asked if enough information was provided during her pregnancy, Shiloh expressed, I was just working off my own mind...I... had no help from doctors... I had to learn by myself (Shiloh, age 19). This fear of neglect extended to the current state of the NHS and possible funding cuts; Midwifes, are getting paid less... and it's going to mess up the NHS... it will go back to where people are having their kids at home themselves... where they're giving birth to their own child (Shiloh, age 19). Shiloh did not vaccinate during pregnancy and reported no trust in HCW advice on vaccination. 
Ten participants had family members who were HCWs, from whom they tended to ask advice. One participant asked her grandfather (a retired doctor) and her step-mother (a paediatrician) for advice. When asking her grandfather about the influenza vaccination during pregnancy, he responded; "You're not allowed to medicate pregnant women and especially vaccines... Don't get anything because there is no research how it will affect an unborn child, it needs to be studied for 20/30 years to know... if there is any effect... don't become a guinea-pig”, (Aldona, age 29, quoting her grandfather). Here again the powerful 'guinea-pig' metaphor is used. Not only is this advice coming from a trusted family member but a family member who is also a HCW. These people tended to be trusted more than nonrelated HCWs.

I would've trusted my sister [who is a midwife] more for honest advice because ...they'd [HCW] be promoting all the... injections... and I've read lots of stories of children being really unwell after having them... a doctor, a nurse wouldn't tell you that, they'd say, "Oh no of course you have to have that" (Anna, age 34).

Trust in friends and family was strong even if that person did not know the answer to a question. When talking about the leader of a parent-toddler group, one participant said;

She's got three kids of her own, so... with her experience ... I felt comfortable with her advice ... It was very reassuring; I didn't feel patronised by her... If she's not sure, she's not sure, but most of the time, when she is sure, it sounds... convincible... so... I can understand what she's saying and I can relate to it (Lucy, age 27). 
From the point of view of the participant, if an advisor was honest, it did not matter if they did not have all the answers. It did not matter that the woman running the toddler-group was not a medic; she listened and was not patronising, she had three children of her own and so could empathise. On the other hand, when a HCW did not have a close relationship with a participant (one participant had been introduced to her midwives as "Midwife 1 and Midwife 2"), the patient could be very scathing. When talking about a midwife who checked for an answer on her phone, the participant called her uneducated and sly (Lucy, age 27). However, according to another participant, when a midwife did admit to not knowing, it was appreciated and they were trusted; My midwife concentrated on my needs... I can ask her anything. Any sort of problems... she always says "I don't know but I can see into it" and she'll get back to me... within that hour (Shiloh, age 19). Often however, questions were not answered and no reassurance provided. Any chances of a trusting relationship were further eroded in some cases by midwives being rude to the patients; Midwives were rather rude... and not so compassionate... not so sympathetic... that affected... my whole experience of my labour (Mahsa, age 31). I asked something, it was ... patronising ... the attitude... how they came across with the answer - it was, like, mm, was I meant to ask you that? (Lucy, age 27). Often however, there was no chance for a relationship to be built. One of the main factors affecting the patientHCW relationships and patient's experience of care was midwife continuity; If you had that same midwife... or if there was someone who knew you I think it would make quite a difference because you could at least trust what they had to say... at least trust one person when people are telling [you] different things (Julia, age 38). One participant expressed the want for a HCW to take time to discuss her concerns and ask her what she was comfortable with so that they can actually understand you as a person (Lucy, age 27). Often, if advice came from a trusted source, even if this person was 'unqualified' in the subject matter, individuals were likely to follow their advice. If a person offering advice was highly qualified but did not have a close 
relationship with the person asking, or if they had a patronising attitude, their advice was sometimes disqualified and distrusted.

\section{Empowerment}

According to Kabeer (1999), empowerment is the process by which individuals acquire an ability to make strategic life choices. The ability to exercise choice incorporates three interrelated dimensions: resources (with regards to vaccination, this would include access to healthcare and vaccination); agency (processes of discussion, negotiation and decision making); and achievements (well-being outcomes) (Kabeer N, 1999). Empowerment is essential for relational autonomy but is only possible when one can trust their HCW and the advice they provide. Parents' perceptions about their agency in the vaccination decision have often been neglected as possible drivers of their vaccination behaviour (Fadda $\mathrm{M}$ et al., 2015).

In a study on the MMR vaccine decision, Fadda et al., (2016), found that the majority of parents reported feeling competent and, consequently, autonomous when they could obtain vaccination-related information and guidance from an expert whom they could trust (Fadda M et al., 2016). These sentiments were reflected in my study: if patients trusted HCW advice, they were more empowered to make the decision that was right for them, with support from their HCW.

My midwife... was really, really good, bubbly, had a laugh, my partner would come there and she would make my partner feel shy... and no one makes him feel like that and I felt like I took control with her... I discuss it with her but I make all the decisions (Beth age 22). 
Participants were clear that they did not want to be left to make vaccine decisions alone. Pertussis and (if it is flu season), influenza vaccines, should be recommended at the pregnant patient's 16-week check with her GP, and then at antenatal appointments with her midwife. However, when and how (and sometimes if) these discussions happen, vary by GP practice and individual HCWs. One of the HCWs interviewed said that the discussion about vaccination is a tick box discussion rather than one we invite and another said the discussion is just part of going through all the things that are needed (Dr. Amber, age 29). This approach left some participants feeling unclear about their options and even neglected by their HCW, and distrustful of the whole healthcare system. One participant described a traumatic experience at the hospital. She was given conflicting advice and asked to make decisions herself. Her response was; 'I'm not the doctor, I don't know what's best for me and the baby... no-one knows what they're doing in here" (Ava, age 26). Mothers often had to decide whether or not to vaccinate with no advice from their HCW provided. As a result, some questioned the importance of the vaccines. This is concerning considering that Fadda et al., (2016) found that confidence in vaccine decisions is related to the perceived importance of this decision (Fadda M et al., 2016).

My midwife she laughed at it [vaccination], she said well it's up to what you want to do... No one's stopping you... just do what you want to do... I called him [GP] and he said he was fine with it as well... [not having vaccines]. They just say "we're not here to force you, it's just your decision" (Shiloh, age 19).

I think you have to go with your instinct... if you feel like... you're not getting the right information, then you won't go for it [vaccination]... needs to be a lot more... one to 
one... communication... especially with pregnant women... there needs to be... more... understanding between one another... 'I've understood what you're saying, and what you're saying to me doesn't make me feel like I have to go to somewhere else to get another opinion" ... to make someone feel like they have to do their own investigation... it's like being at school...this is different. This is to do with an unborn... human (Lucy, age 27).

One component of patient-centred care is whether HCWs explicitly solicit questions about vaccination. One participant stated that while HCWs were in general very pro-vaccine, there was no scope for discussion (Idda, age 27). Sometimes participants needed re-assurance, which also tended to be missing from the vaccine conversation.

It's almost taken as a given that if they tell you about it [vaccination]... you'll just do it... as opposed to proactively looking to reassure you, if you haven't specifically asked. So if I had questions... "What are the known side effects?" ... and I'm confident enough to ask that... it's not like they were... withholding anything, but they won't proactively volunteer the information (Isobel, age 40).

In cases like this, the implicit message given to patients who turn to HCWs for advice is that the patient is on their own, and should be able to think clearly about the decision. There is an assumption that being autonomous means being self-reliant and rational. The consequence of this is that the burden of making a decision is carried exclusively by the pregnant patient (Wendler D and Rid A, 2011). Further to this, there was sometimes the assumption that some information was being withheld, reflecting sentiments of other participants of distrust in the government and its organisations. 
When discussing the influenza vaccine, one participant stated that she felt "down" because she did not receive the vaccine during pregnancy. This patient also mentioned that HCWs did not care (Haleefa, age 27). If an in-depth discussion with a trusted HCW had taken place, which accounted for the patient's personal emotions and needs, she may have felt more competent and thus empowered to make the right decision for her. She would be more likely to have felt satisfied and confident with her decision without experiencing feelings of guilt after the decision was made.

An empowered decision could also prevent the phenomenon of 'omission bias', the concept of favouring potentially harmful omissions over less harmful acts. The phenomenon arises because it is often perceived that one is more responsible for the consequences of one's actions than for the consequences of one's inactions, and so the former would cause more blame and regret (Asch DA, 1994). For example, Shiloh, age 19, stated that if something went wrong with her pregnancy after receiving vaccination, she would be annoyed with herself. A decision to vaccinate which is shared with a HCW could lesson these fears of blame and regret.

The way in which the topic of vaccination is initiated is important because it can significantly affect the nature and extent of patients' responses (Opel et al., 2012). A video recording of a sixteen week check consultation between a GP and her pregnant patient in this study showed that the GP had an open, participatory approach to the vaccine discussion. From the start, the GP built a relationship with the patient: she smiled at the baby scan and said; It doesn't matter how many times I see this, I still think it's amazing... its phenomenal. The GP then clearly outlined what will happen in the consultation and, initiating the vaccine discussion by saying that they would have a little chat about vaccines and things like that. Is that kind of 
what you were expecting? The patient expressed how nice it felt to receive the call about the consultation and to be looked after. The GP told the patient she could stop her if she had any questions. She said she would touch on the pertussis vaccine and asked if the patient knew much about the infection and the vaccine. The patient told the GP the story of having whooping cough as a child and being given fish fingers. The GP and patient were able to laugh about this as an idea for a cure. The GP explained why the vaccine was introduced, the dangers of an infant contracting pertussis and when and by whom it would be administered. She asserted that it is rare to have any side effects from the vaccine, reassuring the patient that we keep an eye on you when we give it... but it's incredibly rare to have any kind of allergic reaction ... you should be perfect; you won't notice anything. The patient was able to ask questions during this discussion which were answered confidently and at the end of the discussion, expressed, that makes perfect sense to me. The GP finished the consultation by asking about the patient's mood, if she had a supportive partner, and telling her that she seemed clued up.

From the perspective of the participant, the GP personalised the consultation and showed caring for the individual with true delight in the baby scan, and asking about her emotional needs. She was able to make the patient feel comfortable and at ease by sharing a joke. The question format (ie. have you heard of pertussis?) and the assurance that the patient could ask questions, allowed patient participation in the vaccination decision process (Opel et al., 2012). Any concerns could be discussed and the patient was re-assured. The result of this was that the patient felt cared for and confident in the vaccine recommendation. 


\section{Conclusions}

Patients face many influences on their decisions to vaccinate including family, friends, health professionals, religious institutions and government agencies, as well as their personal characteristics (Ells C et al., 2011). Often pregnant women are greatly influenced by trusted female family members to whom they have approached for advice. The advice given has great influence on a pregnant woman's decision to vaccinate. Social conditions and relationships can even shape available choices for patients (Ells C et al., 2011). It is important therefore that HCWs understand these influences, as well as the wider social context in which their patient is situated. If HCWs know who these influencers are, they are more able to talk through any concerns brought about by them with the patient (possibly by debunking myths and re-assuring confused patients after receiving conflicting advice). The HCW may also then notice that partners are not being engaged in the conversation, as was observed in this study, thus affecting their ability to provide advice and support. HCWs could then engage such family members in discussions about the vaccination decision, unburdening the pregnant patient from making health decisions on her own. This approach would incorporate a broader conception of the patient's needs in context (Walter JK and Friedman Ross L, 2014), while engaging in a dialogue about how vaccines make sense in people's lives and thus engendering a feeling of understanding and trust between the HCW and patient. For this understanding to arise (which entails in-depth discussion of a very personal nature, sometimes including patient's family members), pregnant patients must trust their HCWs.

While some participants in this study had a close relationship with their $\mathrm{HCW}$, in many cases, good patient-HCW relationships and understanding of the patient's social context was lacking and so distrust in HCWs and vaccination was not surprising. A relational autonomy approach requires the same one or two HCWs to spend time with their patient during her 
pregnancy, to understand the contextual features of her identity and experience, including key relationships with others, and the role the patient wishes herself and others to play. These features of a relational autonomy approach help the HCW to understand the patient as a whole, and foster a relationship of collaboration between patient and health professional, as well as address any circumstances that hinder patient autonomy (Ells C et al., 2011).

The role of the HCW therefore is not only to provide information but also to build a trusting, close relationship with their patient, ensuring she feels comfortable, taken care of, and in control. In this way, HCWs can be key in patient's empowerment in the vaccination decision. They should be willing to address parents' questions and concerns and recognise how their interactions and relationships with patients can either enable or impair empowerment. Misconceived assumptions about what empowerment means might be a contributing factor to vaccine hesitancy (Fadda M et al., 2016). It must be understood that patients can at the same time be compliant with the $\mathrm{HCW}$ recommendation, but claim the decision as their own as it was guided by a trusted source with whom they have a good relationship (Kukla R, 2005). In fact, patients feel more in control of their decision when it is recommended by a trusted medical professional (Mendick $\mathrm{N}$ et al., 2010). Thus, to feel empowered does not necessarily mean patients must make decisions on their own. Having the ability to negotiate the extent to which one is involved in decision-making is key; it is a wholly context-specific decision (Jackson C et al., 2008). These features of relational autonomy lead not only to greater patient satisfaction, less symptom burden, and lower rates of referral (Little P et al., 2001) but could also increase levels of trust in vaccination and thus create higher rates of vaccination acceptance. 
Those who do not accept prescribed vaccination schedules should be seen neither as ignorant nor as resisting in a negative sense. Such assumptions lead to flawed and ineffective policy prescriptions (Poltorak M et al., 2005). Such parents are often following positive, informed strategies geared to their health, which understand vaccination in personalised ways. The current popularity of individualist thinking makes the 'one size fits all' vaccine programme and the discourse of herd immunity seem impersonal, without much scope for patient inclusion in the decision-making process. Therefore, individualised care may create a more positive experience of healthcare (Reich J, 2016). If policy-makers and health professionals are to engage effectively with mothers, one-way information delivery needs to be replaced with dialogue that appreciates and understands the social processes around vaccination concerns (Poltorak M et al., 2005). Health professionals should move away from implicit expectations of compliance, incorporating definitions of science and evidence to include a wider variety of views (Leach M and Fairhead J, 2007). This would open it up to public critique and thus create a more democratized health care system. 


\section{References}

ASCH DA 1994. Omission Bias and Pertussis Vaccination. Med Decis Making, 14, 118-23.

BRAUN V \& CLARKE V 2014. What can thematic analysis offer health and wellbeing researchers? International Journal of Qualitative Studies on Health and Well-being, 9.

BYRNE L. 30th June 2015. RE: Registered Patient GP practice data. Prenatal pertussis Immunisation Vaccine Uptake Monitoring Programme England Apr 2015 to Mar 2016. Type to WILSON R.

DLUGACZ Y, FLEISCHER A, TORROELLA CARNEY M, COPPERMAN N, AHMED I \& ROSS Z 2012. 2009 H1N1 vaccination by pregnant women during the 2009-10 H1N1 influenza pandemic. Obstetrics, 206, 339.e1-339.e8.

ELLS C, HUNT MR \& CHAMBERS-EVANS J 2011. Relational autonomy as an essential component of patient-centered care. International Journal of Feminist Approaches to Bioethics, 4, 79-101.

FADDA M, DEPPING, MK \& SCHULZ PJ 2015. Addressing issues of vaccination literacy and psychological empowerment in the measles-mumps-rubella (MMR) vaccination decisionmaking: a qualitative study. BMC Public Health, 14.

FADDA M, GALIMBERTI E, CARRARO V \& SCHULZ PJ 2016. What are parents' perspectives on psychological empowerment in the MMR vaccination decision? A focus group study. BMJ Open, 6.

FLORY, D. 2012. Commissioning the pertussis (whooping cough) vaccination programme for pregnant women [Online]. Available:

https://www.gov.uk/government/uploads/system/uploads/attachment data/file/212948/D avid-Flory-PERTUSSIS-27-09-2012.pdf. [Accessed 15th September 2014].

JACKSON C, CHEATER FM \& REID I 2008. A systematic review of decision support needs of parents making child health decisions. Health Expect, 11, 232-51.

JOFFE H 2003. Risk: From perception to social representation. British Journal of Social Psychology, $42,55-73$.

KABEER N 1999. Resources, Agency, Achievements: Reflections on the Measurement of Women's Empowerment. Development and Change, 30

KUKLA R 2005. Conscientious autonomy: displacing decisions in health care. Hastings Cent Rep, 35, 34-44.

KUMAR R 2013. How are Women's experiences of childbirth represented in the Literature? A critical review of qualitative health research set in the global South. Women's Health Urban Life, 12, 19-38.

LB HACKNEY POLICY TEAM. 2016. A profile of Hackney, its people and place [Online]. London: LB Hackney Policy Team. Available: http://hackney.gov.uk/Assets/Documents/HackneyProfile.pdf.

LEACH M \& FAIRHEAD J 2007. Vaccine anxieties: Global science, child health and society, UK, USA, Earthscan.

LITTLE P, EVERITT H, WILLIAMSON I, WARNER G, MOORE M, GOULD C, FERRIER K \& PAYNE S 2001. Observational study of effect of patient centeredness and positive approach on outcomes of general practice consultations. BMJ, 908-11.

LÖFSTEDT RE 2005. Risk Management in Post-Trust Societies, New York, Palgrave Macmillan.

MACKENZIE C \& STOLJAR N 2000. Relational Autonomy: Feminist Perspective on Autonomy, Agency, and the Social Self, New York Oxford University Press.

MAYO E 1949. Hawthorne and the Western Electric Company, the social problems of an industrial civilisation, Massachusetts Routledge.

MCINTYRE P \& N, W. 2009. Pertussis in early infancy: disease burden and preventive strategies. Current Opinion in Infectious Diseases, 22, 215-223.

MENDICK N, YOUNG B, HOLCOMBE C \& SALMON P 2010. The ethics of responsibility and ownership in decision-making about treatment for breast cancer: triangulation of consultation with patient and surgeon perspectives. Soc Sci Med, 70, 1904-11. 
OPEL, D. J., ROBINSON, J. D., HERITAGE, J., KORFIATIS, C., TAYLOR, J. A. \& MANGIONE-SMITH, R. 2012. Characterizing providers' immunization communication practices during health supervision visits with vaccine-hesitant parents: A pilot study. Vaccine, 30, 1269-1275.

OUDSHOORN N 2002. Drugs for healthy people: The culture of testing hormonal contraceptives for women and men. In: VAN HETEREN GM \& TANSEY EM (eds.) Biographies of remedies: drugs, medicines, and contraceptives in Dutch and Anglo American healing cultures. Amsterdam: Rodopi.

POLTORAK M, LEACH M, FAIRHEAD J \& J, C. 2005. 'MMR talk' and vaccination choices: an ethnographic study in Brighton. Soc Sci Med, 61, 709-19.

PUBLIC HEALTH ENGLAND. 2016. Seasonal influenza vaccine uptake amongst GP Patients in England: Provisional monthly data for 1 September 2015 to 31 January 2016 [Online]. England: Public Health England. Available:

https://www.gov.uk/government/uploads/system/uploads/attachment data/file/503124/Ja nuary 2016 Seasonal flu GP patients 01Sept 31Jan.pdf [Accessed 20th August 2016.

REICH J 2016. Calling the shots: Why parents reject vaccines, New York, New York University Press.

RITCHIE B, RITCHIE B \& RITCHIE J 1997. Nurses' practices and perceptions of family-centered care. Journal of Pediatric Nursing, 12, 214-22.

TAYLOR GW \& USSHER JM 2001. Making sense of S\&M: A discourse analytic account. Sexualities, 4, 293-314.

WALTER JK \& FRIEDMAN ROSS L 2014. Relational Autonomy: Moving Beyond the Limits of Isolated Individualism. Pediatrics, 133, 16-23.

WENDLER D \& RID A 2011. Systematic review: the effect on surrogates of making treatment decisions for others. Ann Intern Med, 154, 336-346.

WHITE L 2005. The needle and the state: Immunizatio nand innoculation in Africa. Or, the practice of un-national sovreignty. Locating the field: The ethnocgraphy of biomedical research in Africa. Kilifi, Kenya.

WILSON RJ, PATERSON P, JARRETT C \& LARSON HJ 2015. Understanding factors influencing vaccination acceptance during pregnancy globally: A literature review. Vaccine, 33, 6420-9. 